\title{
Toxemia of Pregnancy
}

National Cancer Institute

\section{Source}

National Cancer Institute. Toxemia of Pregnancy. NCI Thesaurus. Code C34943.

A pregnancy induced hypertensive state that occurs after 20 weeks of gestation

characterized by an increase in blood pressure, along with body swelling and proteinuria. 